\title{
Reverse Hierarchy of Alkane Adsorption in Metal- Organic Frameworks (MOFs) Revealed by Immersion Calorimetry
}

\section{Supporting Information}

Carlos Cuadrado-Collados, ${ }^{1}$ Cintia K. Rojas-Mayorga,${ }^{1}$ Beatriz Saavedra,,${ }^{1}$ Manuel MartínezEscandell, ${ }^{1}$ Jacek M. Osiński, ${ }^{2}$ Peyman Z. Moghadam, ${ }^{3}$ David Fairén-Jimenez, ${ }^{2}$ Joaquin Silvestre-Albero ${ }^{1, *}$

${ }^{1}$ Laboratorio de Materiales Avanzados, Departamento de Química Inorgánica-Instituto Universitario de Materiales, Universidad de Alicante, Ap. 99, E-03690 San Vicente del Raspeig, Spain

${ }^{2}$ Adsorption \& Advanced Materials Laboratory (AAML), Department of Chemical Engineering \& Biotechnology, University of Cambridge, Philippa Fawcett Drive, Cambridge CB3 OAS, UK ${ }^{3}$ Depatment of Chemical and Biological Engineering, University of Sheffield, Mappin Street, Sheffield S1 3JD, UK 


\section{Framework and adsorbate models}

Lennard-Jones (ப) parameters for all framework atoms were taken from the DREIDING force field [1] where available and from the Universal Force Field [2] otherwise. All LJ parameters for the hexane isomers were taken from the united-atom TraPPE model (UA-TraPPE) [3].

Table S1. Lennard-Jones parameters for framework atoms.

\begin{tabular}{cccc}
\hline atom & $\boldsymbol{\varepsilon} / \boldsymbol{k}_{\mathrm{B}}(\mathbf{K})$ & $\boldsymbol{\sigma}(\AA)$ & force field \\
\hline $\mathrm{Cu}$ & 2.51 & 3.11 & UFF \\
$\mathrm{Zn}$ & 27.70 & 4.04 & DREIDING \\
$\mathrm{Zr}$ & 34.72 & 2.78 & UFF \\
$\mathrm{C}$ & 47.86 & 3.47 & DREIDING \\
$\mathrm{O}$ & 48.16 & 3.03 & DREIDING \\
$\mathrm{H}$ & 7.65 & 2.85 & DREIDING \\
$\mathrm{N}$ & 38.95 & 3.26 & DREIDING \\
\hline
\end{tabular}

Table S2. Lennard-Jones parameters for hexane isomers atoms.

\begin{tabular}{ccc}
\hline pseudo-atom & $\boldsymbol{\varepsilon} / \boldsymbol{k}_{\mathrm{B}}(\mathbf{K})$ & $\boldsymbol{\sigma}(\AA)$ \\
\hline $\mathrm{CH}_{3}$ & 98 & 3.75 \\
$\mathrm{CH}_{2}$ & 46 & 3.95 \\
$\mathrm{CH}$ & 10 & 4.68 \\
$\mathrm{C}$ & 0.5 & 6.4 \\
\hline
\end{tabular}

Table S3. Bonded Parameters for the TraPPE-UA Force Field.

\begin{tabular}{|c|c|c|c|c|}
\hline stretch & \multicolumn{4}{|c|}{$r_{0}(\AA)$} \\
\hline $\mathrm{CH}_{\mathrm{x}}-\mathrm{CH}_{\mathrm{y}}$ & \multicolumn{4}{|c|}{1.54} \\
\hline bend & \multicolumn{2}{|c|}{$\theta_{0}$} & \multicolumn{2}{|c|}{$k_{\theta} / k_{\mathrm{B}}(\mathrm{K})$} \\
\hline $\mathrm{CH}_{\mathrm{x}}-\left(\mathrm{CH}_{2}\right)-\mathrm{CH}_{\mathrm{y}}$ & \multicolumn{2}{|c|}{114} & \multicolumn{2}{|c|}{62500} \\
\hline $\mathrm{CH}_{x}-(\mathrm{CH})-\mathrm{CH}_{\mathrm{y}}$ & \multicolumn{2}{|c|}{112} & \multicolumn{2}{|c|}{62500} \\
\hline $\mathrm{CH}_{x}-(\mathrm{C})-\mathrm{CH}_{y}$ & \multicolumn{2}{|c|}{109.47} & \multicolumn{2}{|c|}{62500} \\
\hline torsion & $c_{0} / k_{\mathrm{B}}(\mathrm{K})$ & $c_{1} / k_{\mathrm{B}}(\mathrm{K})$ & $c_{2} / k_{B}(K)$ & $c_{3} / k_{\mathrm{B}}(\mathrm{K})$ \\
\hline $\mathrm{CH}_{\mathrm{x}}-\left(\mathrm{CH}_{2}\right)-\left(\mathrm{CH}_{2}\right)-\mathrm{CH}_{\mathrm{y}}$ & 0 & 335.03 & -68.19 & 791.32 \\
\hline $\mathrm{CH}_{\mathrm{x}}-\left(\mathrm{CH}_{2}\right)-(\mathrm{CH})-\mathrm{CH}_{\mathrm{y}}$ & -251.06 & 428.73 & -111.85 & 441.27 \\
\hline $\mathrm{CH}_{\mathrm{x}}-\left(\mathrm{CH}_{2}\right)-(\mathrm{C})-\mathrm{CH}_{\mathrm{y}}$ & 0 & 0 & 0 & 461.29 \\
\hline $\mathrm{CH}_{\mathrm{x}}-(\mathrm{CH})-(\mathrm{CH})-\mathrm{CH}_{\mathrm{y}}$ & -251.06 & 428.73 & -111.85 & 441.27 \\
\hline
\end{tabular}




\section{Immersion calorimetry measurements}

Table S4. Enthalpy of immersion (J/g) into liquids of different molecular dimension for ZIF-8, HKUST-1 and UiO-66.

\section{Enthalpy of immersion}

$$
-\Delta H_{i m m}(\mathrm{~J} / \mathrm{g})
$$

\begin{tabular}{ccccccc} 
Sample & $\begin{array}{c}\text { DCM } \\
(\mathbf{0 . 3 3} \mathrm{nm})\end{array}$ & $\begin{array}{c}\mathrm{n}-\mathrm{hx} \\
(\mathbf{0 . 4 3} \mathrm{nm})\end{array}$ & $\begin{array}{c}\mathbf{2 - M P} \\
(\mathbf{0 . 5 0} \mathrm{nm})\end{array}$ & $\begin{array}{c}\mathbf{2 , 2} \text {-DMB } \\
(\mathbf{0 . 6 2} \mathrm{nm})\end{array}$ & $\begin{array}{c}\boldsymbol{\alpha} \text {-pinene } \\
(\mathbf{0 . 7} \mathrm{nm})\end{array}$ & $\begin{array}{c}\mathbf{1 , 3 , 5}-\mathrm{TIPB} \\
(\mathbf{0 . 8 5} \mathrm{nm})\end{array}$ \\
\hline ZIF-8 & 88 & 65 & 25 & 3 & 6 & --- \\
HKUST-1 & 260 & 167 & 192 & 174 & 115 & 16 \\
UiO-66 & 108 & 64 & 80 & 119 & 105 & 64
\end{tabular}




\section{Samples characterization}

\section{$X$-ray diffraction patterns}
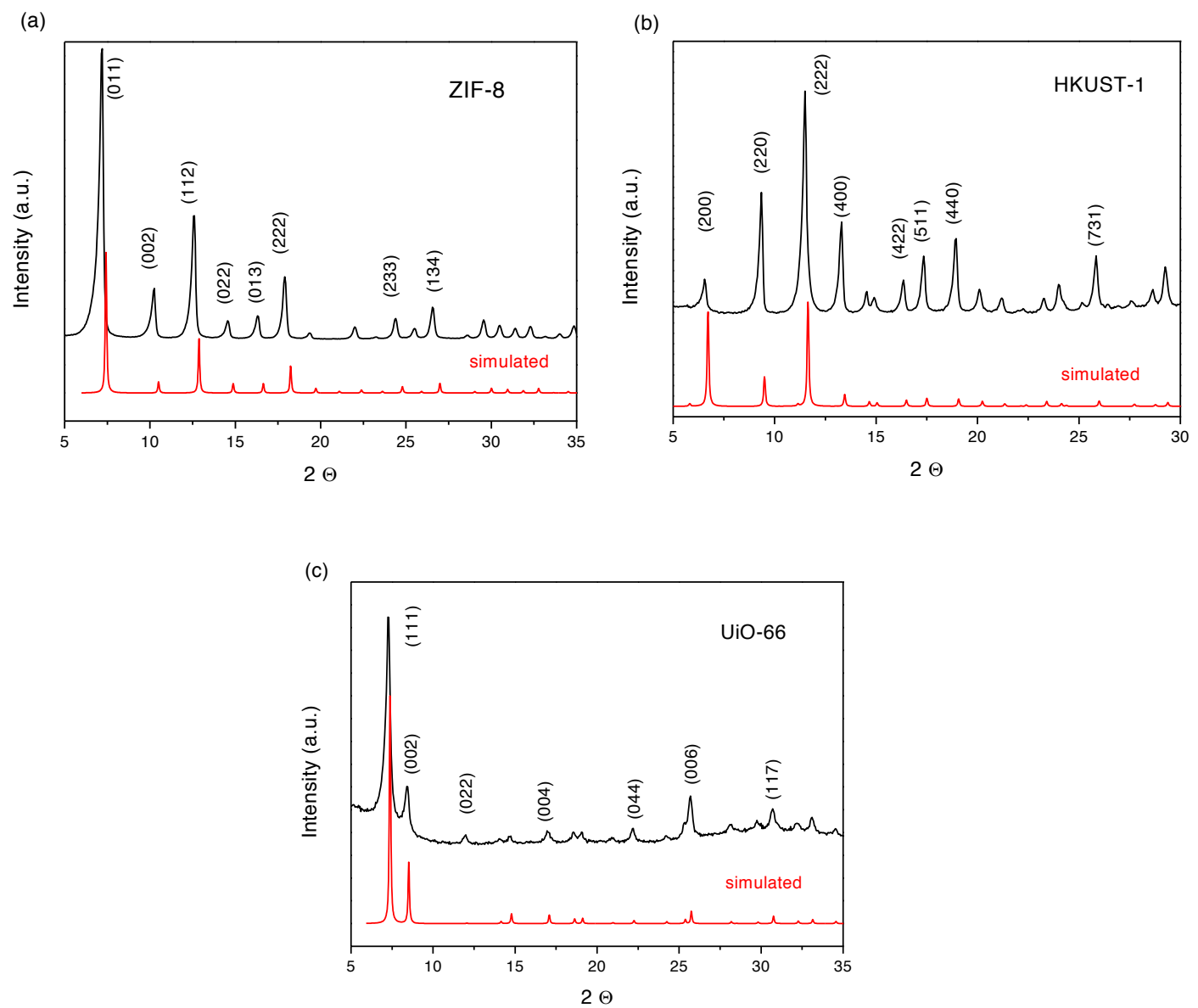

Figure S1. PXRD patterns for the different MOFs evaluated. All figures include the simulated pattern obtained with Mercury program available at the Cambridge Crystallographic Data Centre. 


\section{Nitrogen and Ar adsorption isotherms at $77 \mathrm{~K}$}

Nitrogen adsorption in ZIF-8 is favored at lower relative pressures compared to $\mathrm{Ar}$ (see Figure $\mathrm{S} 2$ ). Indeed, micropore filling for nitrogen starts already below $\mathrm{p} / \mathrm{p}_{0}=10^{-4}$ whereas $\mathrm{Ar}$, at the same temperature, requires larger relative pressures. For both probe molecules the adsorption isotherm exhibits a first step below $10^{-3}$, which has been attributed to the filling of the inner cavity in ZIF-8, and a large condensation at relative pressures close to 1 due to the expansion of the unit cell upon gas adsorption, as suggested by DFT calculations [4]. Interestingly, in the specific case of nitrogen there is an additional intermediate step at $10^{-2}$. Inelastic neutron scattering measurements from our research group have attributed this step to the swinging of the imidazole linkers due to the adsorbate-adsorbent interactions for $\mathrm{N}_{2}$ $[4,5]$. A similar situation occurs for HKUST-1. Micropore filling for nitrogen occurs at lower relative pressures compared to argon, most probably due to the presence of specific interactions between the nitrogen molecule and the open Lewis acid centers in HKUST-1. In any case, at higher relative pressure argon adsorption overpass nitrogen in both MOFs due to the larger density of the former. Last but not least, UiO-66 exhibits a similar profile for both probe molecules with no specific adsorbate-framework interactions. As described above, the larger adsorption capacity for argon at high relative pressures is attributed to the larger density of Ar compared to $\mathrm{N}_{2}$. Assuming that the pores are filled with a liquid adsorptive of bulk-like properties (liquid density of $1.4 \mathrm{~g} / \mathrm{cm}^{3}$ and $0.808 \mathrm{~g} / \mathrm{cm}^{3}$ for $\mathrm{Ar}$ and $\mathrm{N}_{2}$, respectively), all samples exhibit a relatively good agreement between the $V_{\mathrm{N} 2}$ and $V_{A r}$, i.e. all samples fulfill the Gurvich rule at relative pressure close to 1 (see Table 1 in the main manuscript). $\mathrm{N}_{2}$ and $\mathrm{Ar}$ data at $77 \mathrm{~K}$ have also been used to calculate the BET surface area. As it can be observed in Table 1, there is a quite good agreement between the textural parameters obtained with both probe molecules, mainly in the micropore and total pore volume, while large differences are encountered in the BET area (effective cross-sectional area for nitrogen considered is 0.162 $\mathrm{nm}^{2}$ and $0.138 \mathrm{~nm}^{2}$ for argon). However, it is important to emphasize that the estimation of the BET area in MOFs is not straightforward and care must be taken due to the difficulty in certain MOFs to identify a proper linear range for the application of the BET equation (due to specific interactions with the framework, breathing phenomena, gate-opening effects, etc.). In any case, recent molecular grand canonical Monte Carlo simulations have described a good agreement between the experimental BET area, the BET from the simulated isotherms and the one estimated from the crystal structure [6]. 

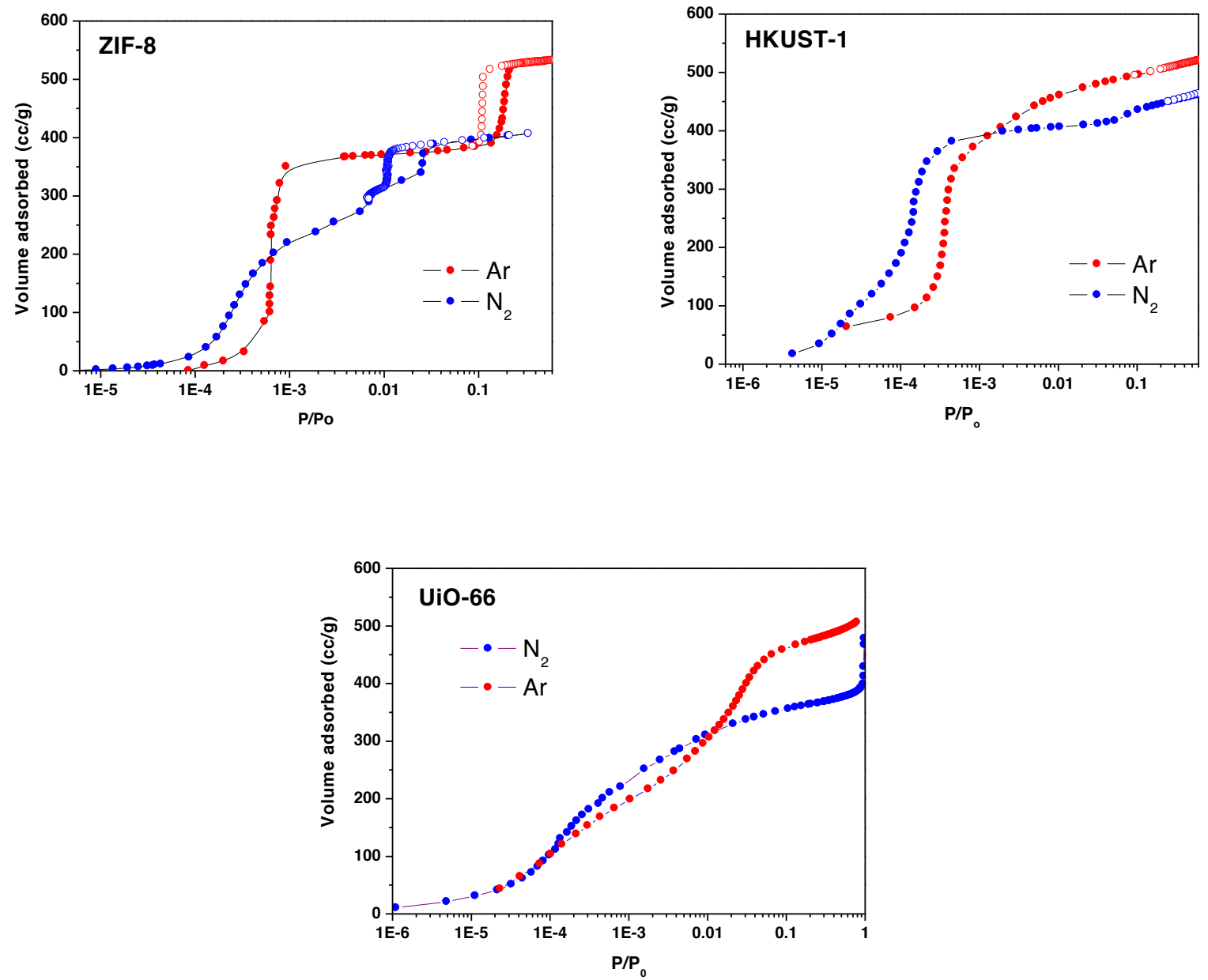

Figure S2. $\mathrm{N}_{2}$ and Ar adsorption isotherms at $77 \mathrm{~K}$ (logarithmic scale) for the different MOFs evaluated. 


\section{Adsorption in ZIF-8}

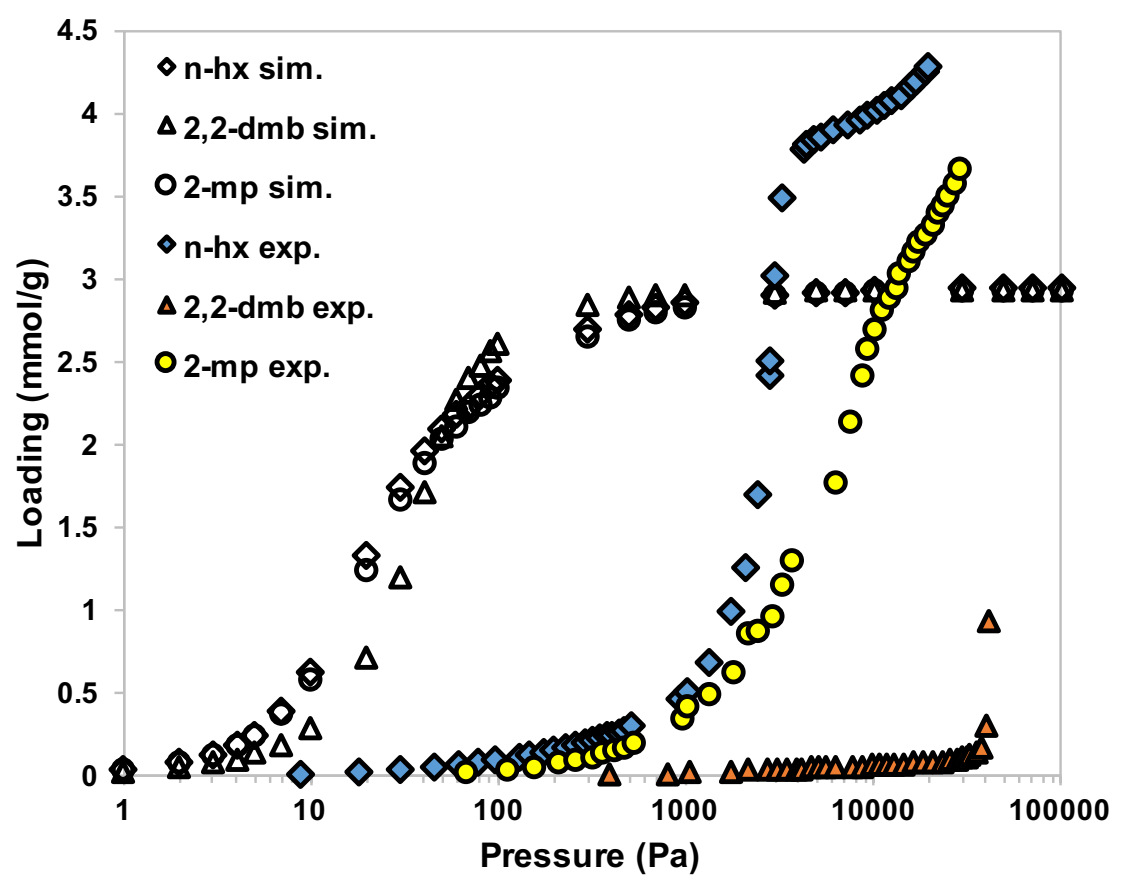

Figure S3. Comparison of experimental and simulated adsorption isotherms for ZIF-8 (open structure). Empty symbols - simulations; closed symbols - experiments; diamonds - nhexane, triangles - 2,2-DMB, circles - 2-MP.

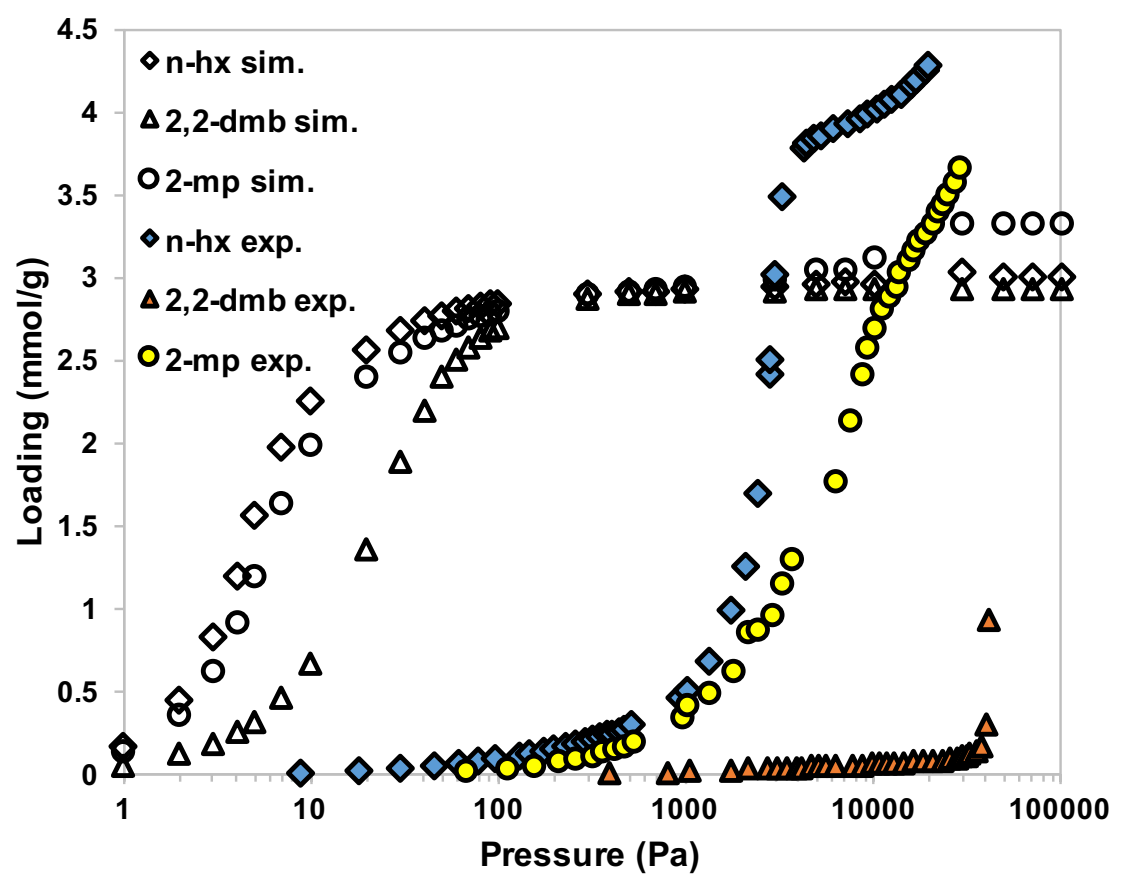

Figure S4. Comparison of experimental and simulated adsorption isotherms for ZIF-8 (closed structure). Empty symbols - simulations; closed symbols - experiments; diamonds - $n$ hexane, triangles - 2,2-DMB, circles - 2-MP. 
a)

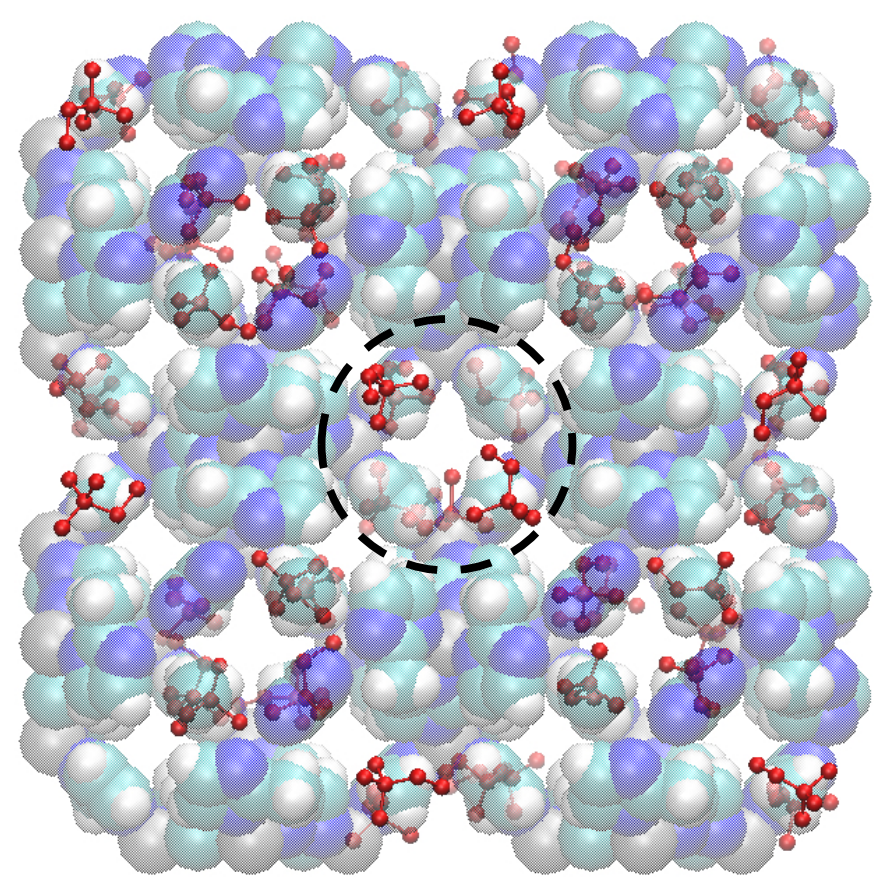

b)

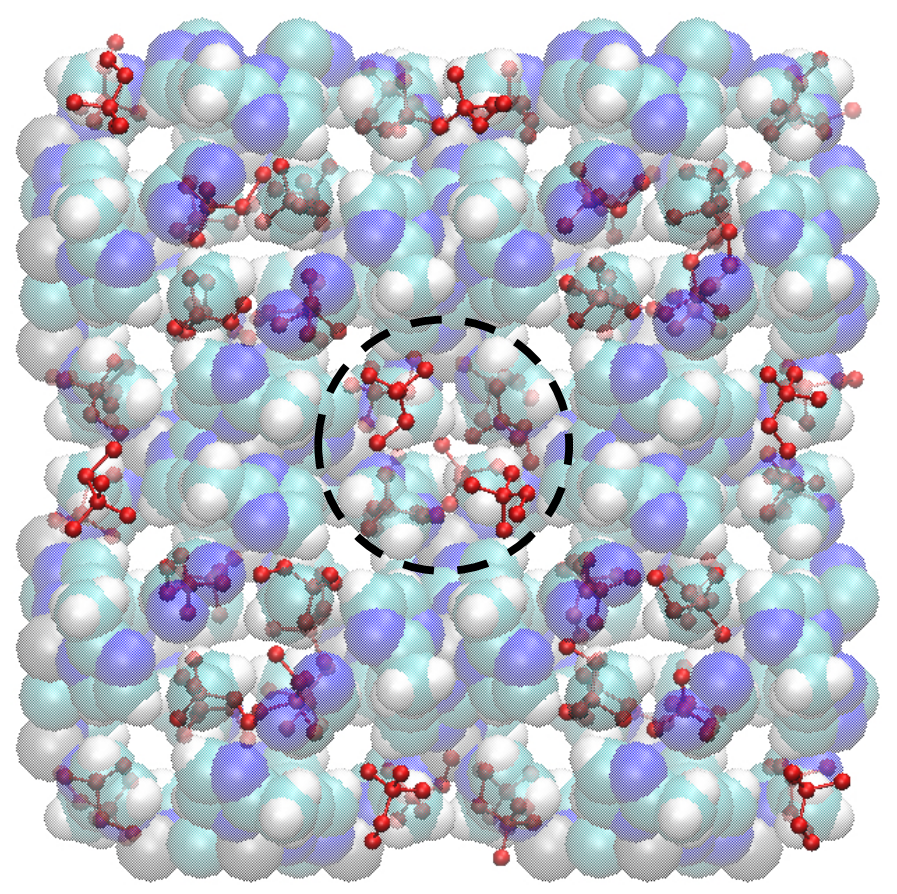

Figure S5. 2,2-DMB in ZIF-8 simulation snapshots at 1 bar showing a) the open structure and b) the closed structure. The windows connecting the large cavities, which differ between the two structures are marked with the dashed circle. 


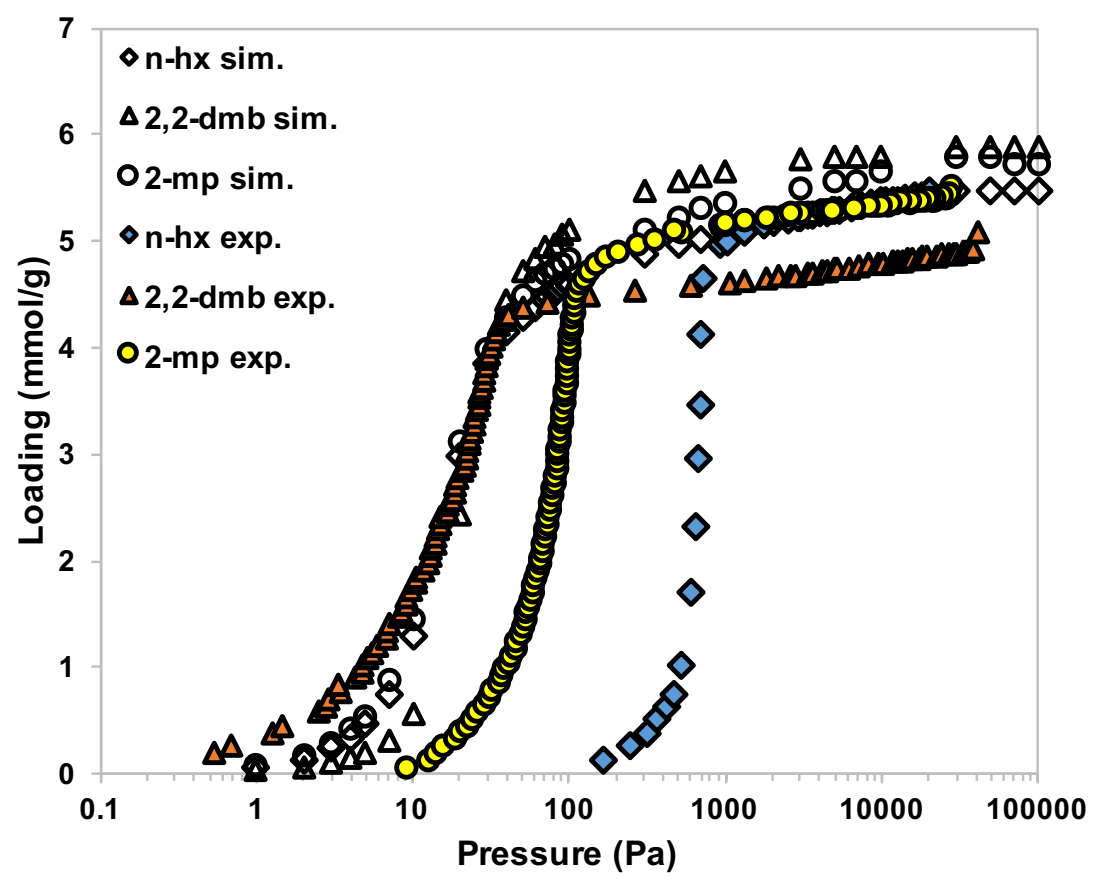

Figure S6. Comparison of experimental and simulated adsorption isotherms for HKUST-1. Empty symbols - simulations; closed symbols - experiments; diamonds - $n$-hexane, triangles -2,2-DMB, circles - 2-MP.

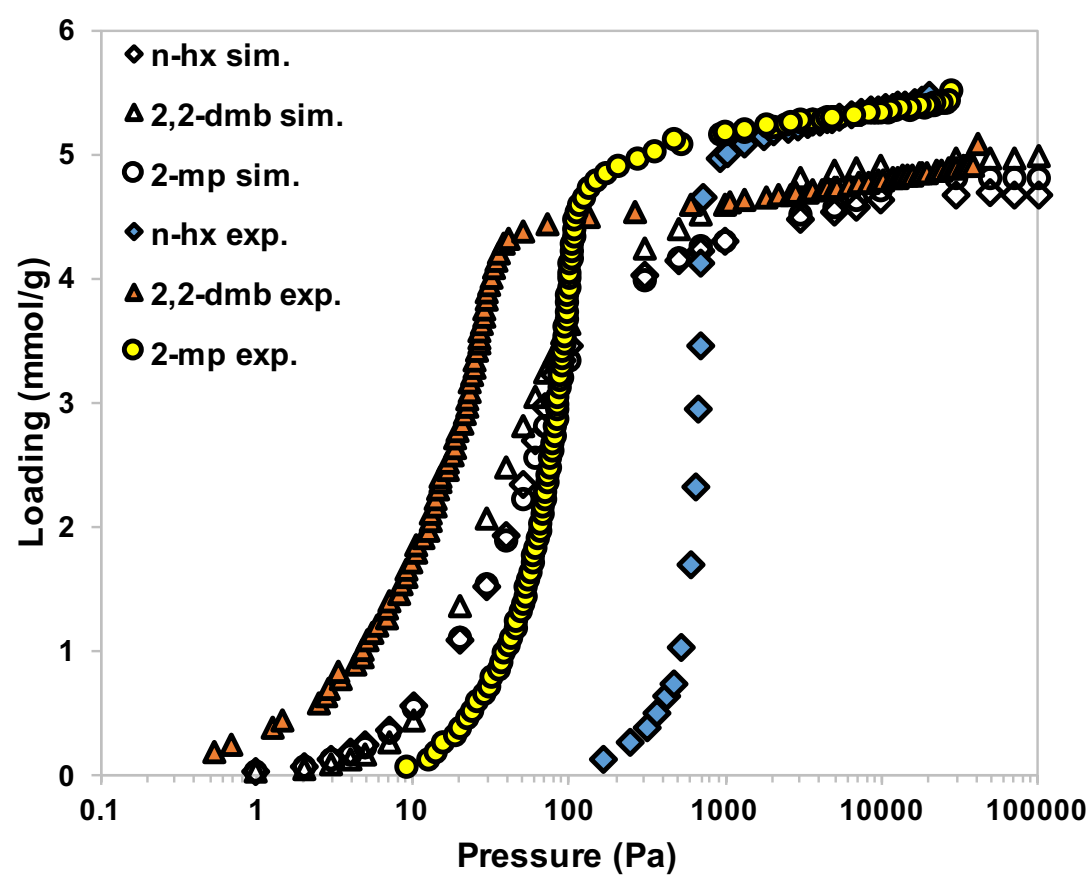

Figure S7. Comparison of experimental and simulated adsorption isotherms for HKUST-1 with smaller pores blocked. Empty symbols - simulations; closed symbols - experiments; diamonds - n-hexane, triangles - 2,2-DMB, circles - 2-MP. 


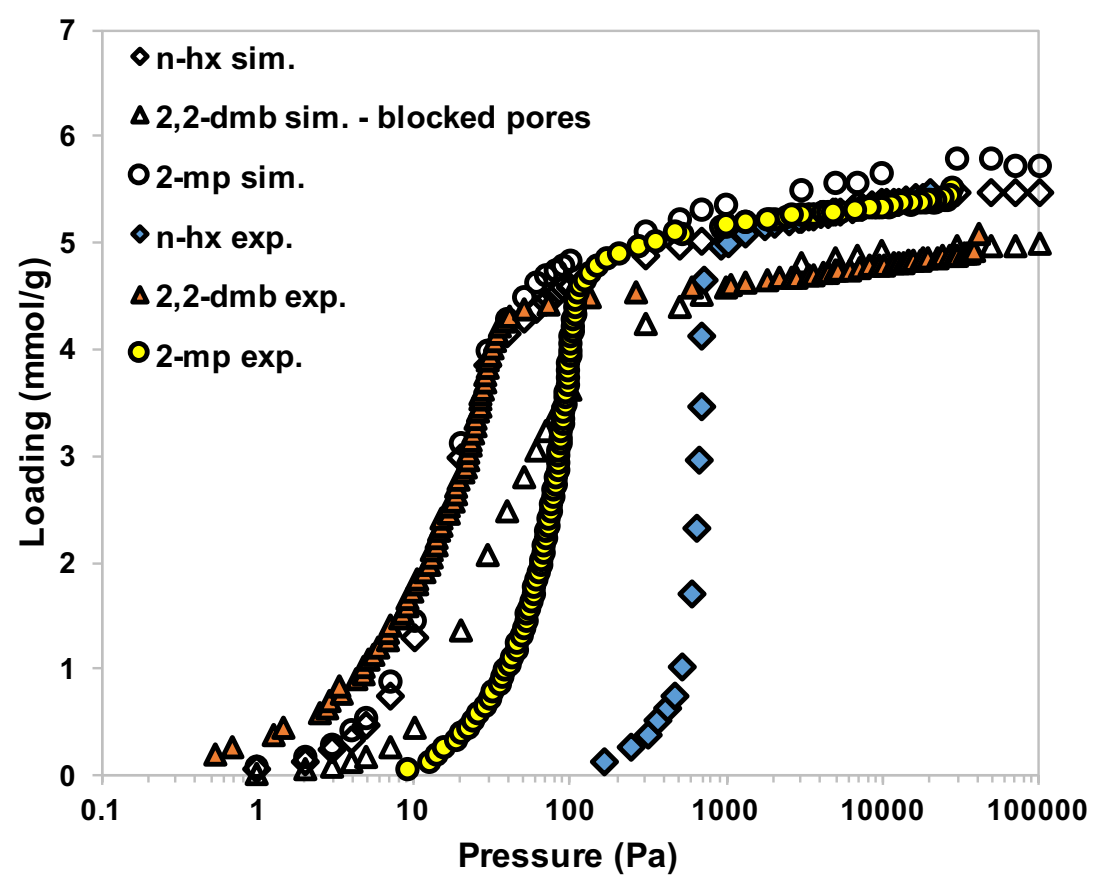

Figure S8. Comparison of experimental and simulated adsorption isotherms for HKUST-1 with smaller pores blocked only for 2,2-DMB. Empty symbols - simulations; closed symbols experiments; diamonds - n-hexane, triangles - 2,2-DMB, circles - 2-MP. 
a)

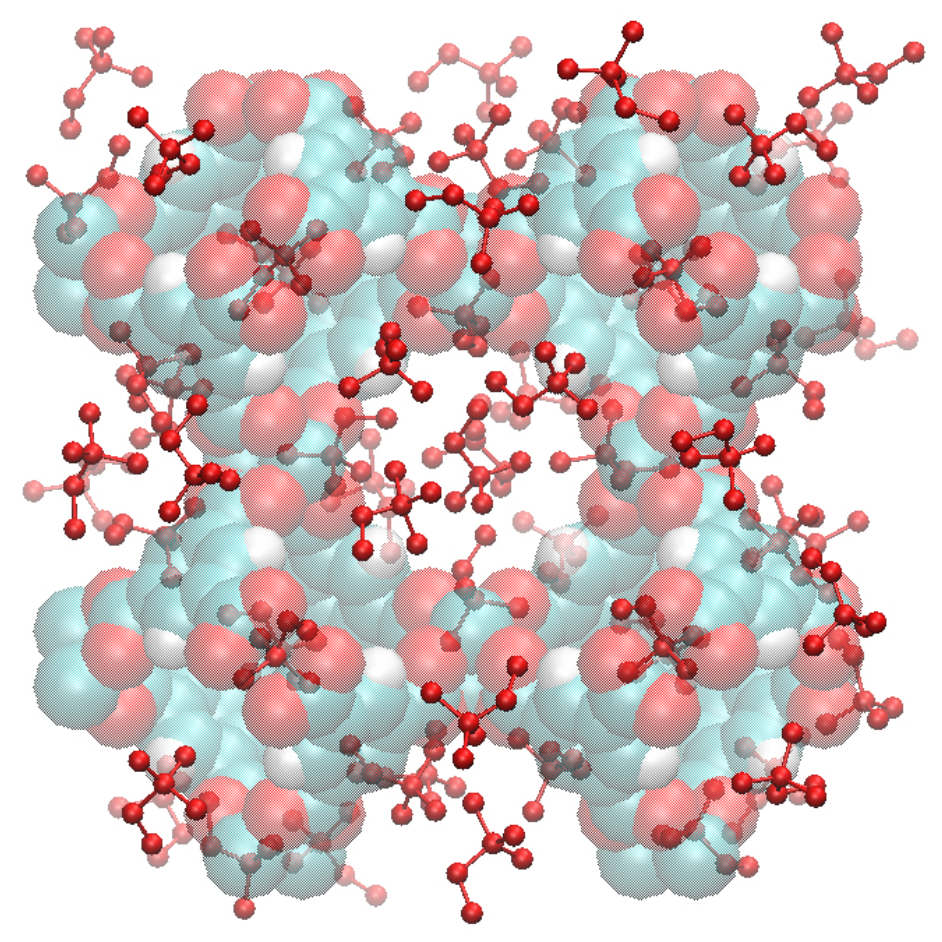

b)

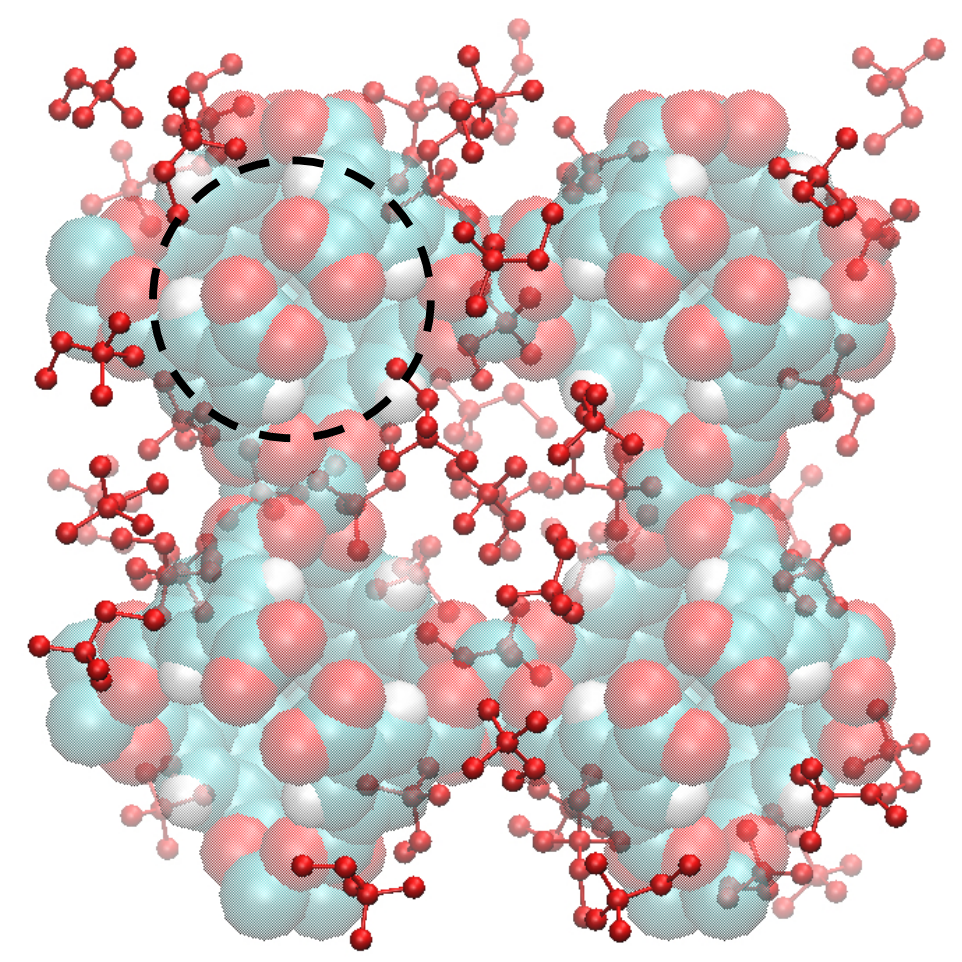

Figure S9. 2,2-DMB in HKUST-1 simulation snapshots at 1 bar a) without pore blocking and b) with the smaller pores (marked with the dashed circle) blocked. 


\section{Adsorption in UiO-66}

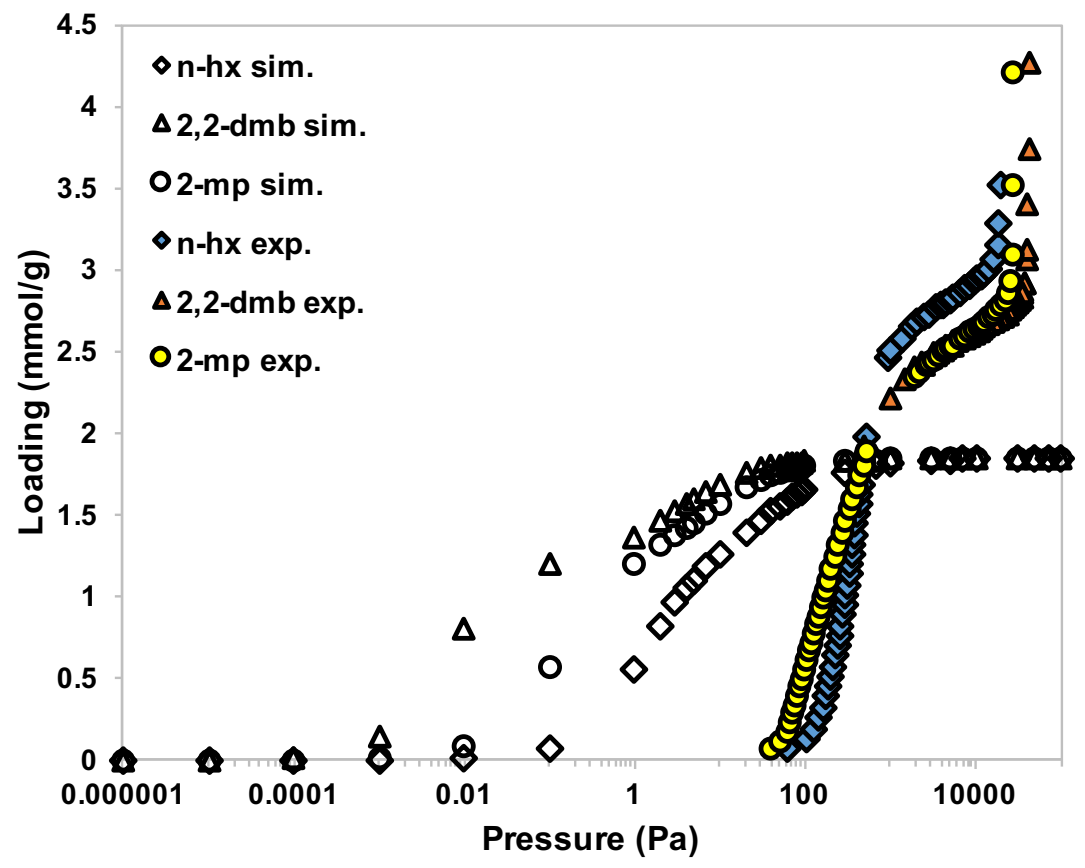

Figure S10. Comparison of experimental and simulated adsorption isotherms for UiO-66.

Empty symbols - simulations; closed symbols - experiments; diamonds - $n$-hexane, triangles $-2,2-\mathrm{DMB}$, circles - 2-MP. 
a)

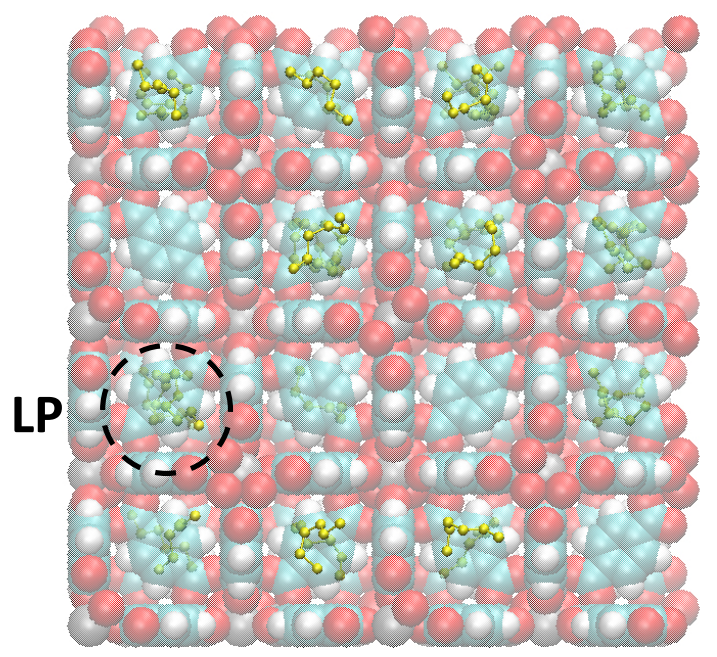

b)

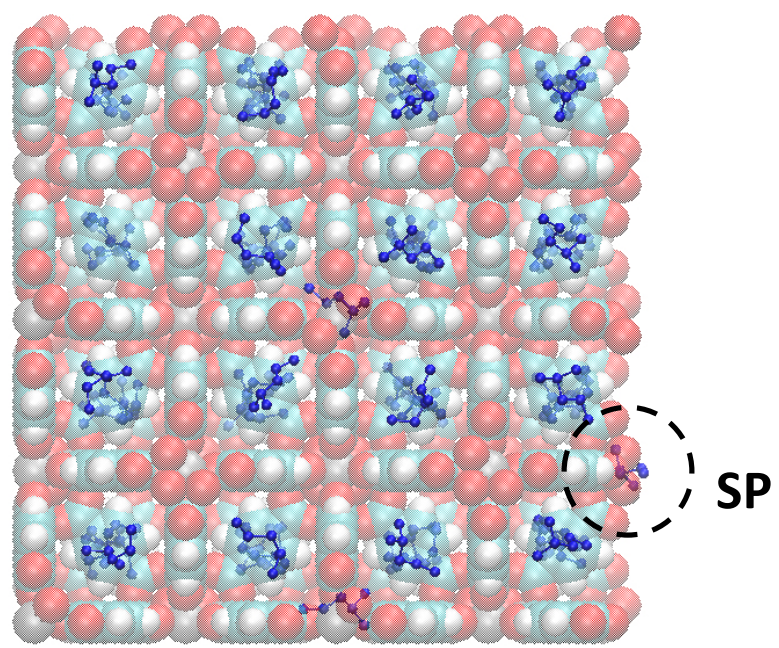

c)

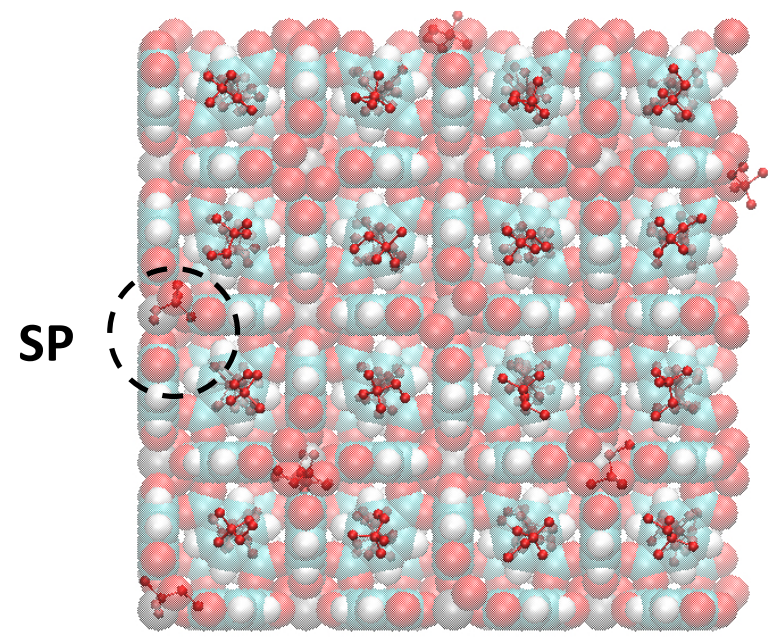

Figure S11. Simulation snapshots of a) n-hexane (yellow), b) 2-MP (blue), c) 2,2-DMB (red) in UiO-66 at $1 \mathrm{~Pa}$. At this pressure, $\mathrm{n}$-hexane only occupies the larger pores (marked "LP"), however 2-MP and 2,2-DMB already start to fill the smaller pores (marked "SP"). 
a)

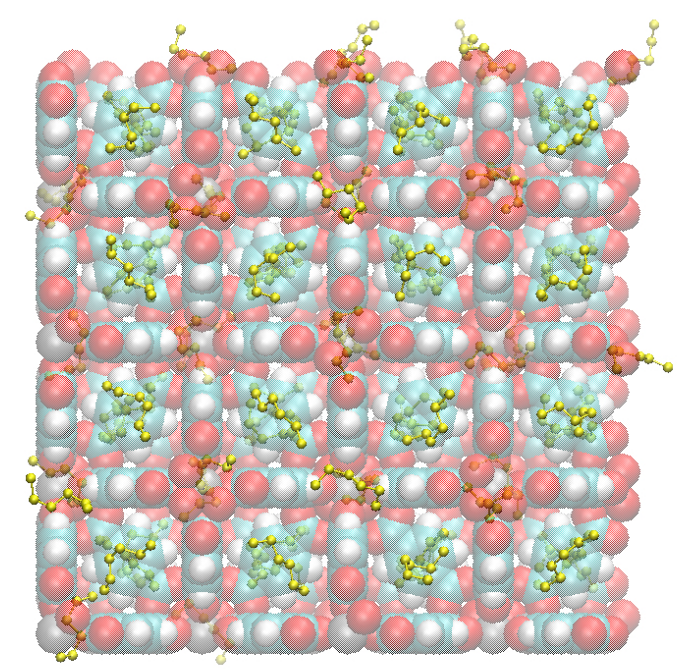

b)

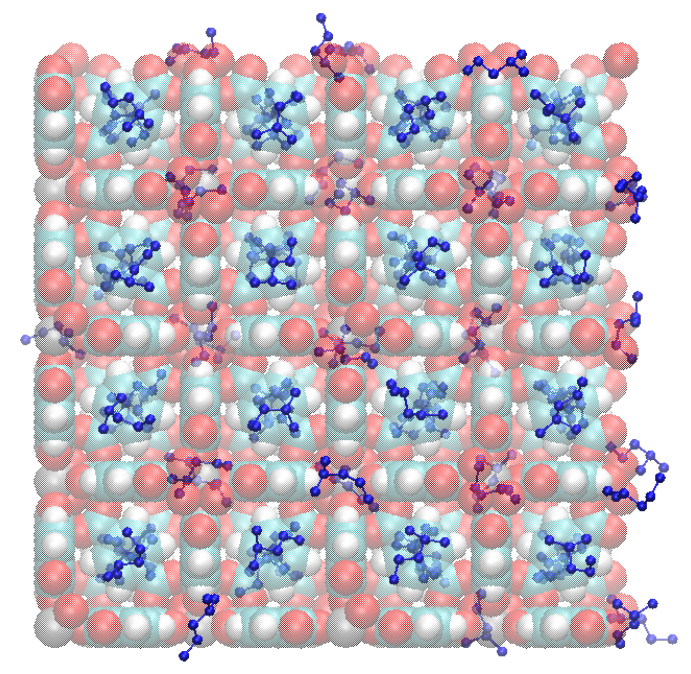

c)

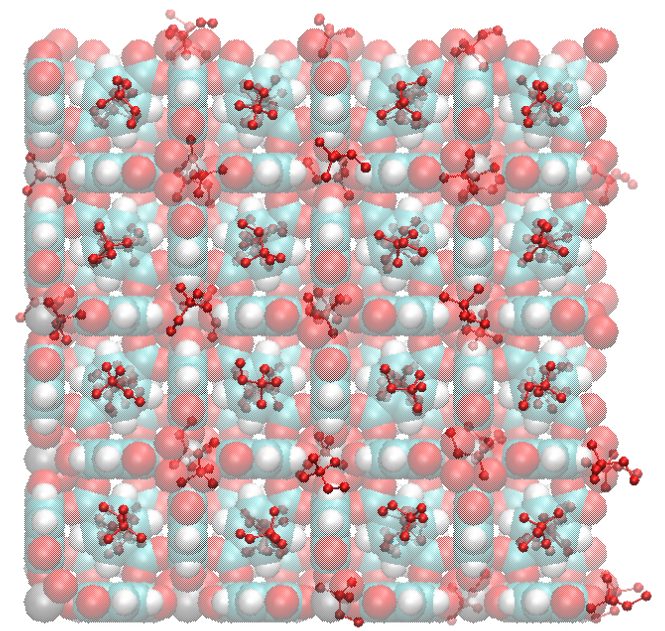

Figure S12. Simulation snapshots of a) n-hexane (yellow), b) 2-MP (blue), c) 2,2-DMB (red) in UiO-66 at 1 bar (saturation). All pores of both sizes are filled with exactly one adsorbate molecule, thus leading to equal saturation loading $(\sim 2.0 \mathrm{mmol} / \mathrm{g})$ for all three isomers.

\section{References}

[1] S. L. Mayo, B. D. Olafson, W. a G. lii, E. Eb, and E. a E. T. El, "DREIDING: A Generic Force Field for Molecular Simulations", J. Phys. Chem., vol. 101, no. Suite 540, pp. 8897-8909, 1990.

[2] A. K. K. Rappé, C. J. J. Casewit, K. S. S. Colwell, W. A. Goddard III, and W. M. Skiff, "UFF, a Full Periodic Table Force Field for Molecular Mechanics and Molecular Dynamics 
Simulations", J. Am. Chem. Soc., vol. 114, no. 25, pp. 10024-10035, 1992.

[3] M. G. Martin and J. I. Siepmann, "Novel Configurational-Bias Monte Carlo Method for Branched Molecules. Transferable Potentials for Phase Equilibria. 2. United-Atom Description of Branched Alkanes", pp. 4508-4517, 1999.

[4] M.E. Casco, Y.Q. Cheng, L.L. Daemen, D. Fairen-Jimenez, E.V. Ramos-Fernandez, A.J. Ramirez-Cuesta, J. Silvestre-Albero, "Gate-opening effect in ZIF-8: the first experimental proof using inelastic neutron scattering", Chem. Commun., 52 (2016) 36393642.

[5] D. Fairen-Jimenez, S.A. Moggach, M.T. Wharmby, P.A. Wright, S. Parsons, T. Düren, "Opening the gate: Framework flexibility in ZIF-8 explored by experiments and simulations", J. Am. Chem. Soc., (2011) 8900-8902.

[6] D.A. Gómez-Gualdrón, P.Z. Moghadam, J.T. Hupp, O.K. Farha, R.Q. Snurr, "Application of consistency criteria to calculate BET areas of micro and mesoporous metal-organic frameworks", J. Am. Chem. Soc., 138 (2016) 215-224. 